\title{
Re-intervention with endoscopic ultrasound-guided hepaticogastrostomy for unresectable hilar biliary drainage using a multipath occlusion balloon
}

Endoscopic ultrasound (EUS)-guided hepaticogastrostomy (EUS-HGS) and antegrade stenting (EUS-AS) have been developed as alternative biliary drainage methods; however, treating unresectable malignant hilar biliary strictures remains challenging [1-3]. We successfully performed re-intervention for malignant hilar biliary drainage after EUS-HGS using a multipath occlusion balloon.

A 46-year-old woman who was on medication for a postoperative recurrence of gastric cancer presented with jaundice. She had previously undergone doubleballoon enteroscope (DBE)-assisted biliary drainage with a self-expandable metal stent (SEMS) for malignant biliary stricture of the lower bile duct.

Contrast-enhanced computed tomography (CT) showed strictures of the hilar bile duct and duodenum (\$ Fig.1) associated with dissemination of the gastric cancer. EUS-HGS was performed (\$ Fig.2), and a 7-Fr plastic stent (TYPEIT; Gadelius Medical, Tokyo, Japan) was placed into the B3 bile duct [4]. However, the patient's jaundice was not improved, and re-intervention was required. A 0.025-inch guidewire was placed into the duodenum beyond the papilla, and the plastic stent was removed. A second 0.025 -inch guidewire was placed into the B5 bile duct using a multipath occlusion balloon (Bouncer; Cook Medical, Tokyo, Japan) (> Fig.3). This balloon has a multilumen located at either end of the balloon, which enables guidewires to be passed easily into crooked bile ducts ( $\triangleright$ Fig. 3 and $>$ Fig. 4 a; $>$ Video 1). A Zilver 635 biliary SEMS (Cook Medical, Tokyo, Japan) was introduced over the first guidewire and placed into the B5 bile duct, bridging the right and left hepatic ducts ( $>$ Fig.4b). Finally, a modified Niti-S GIOBOR biliary stent (Century Medical, Tokyo, Japan) was placed into the B3 bile duct ( $\triangleright$ Fig. $4 \mathbf{c}$ ). The jaundice subsequently improved, and no adverse events occurred.

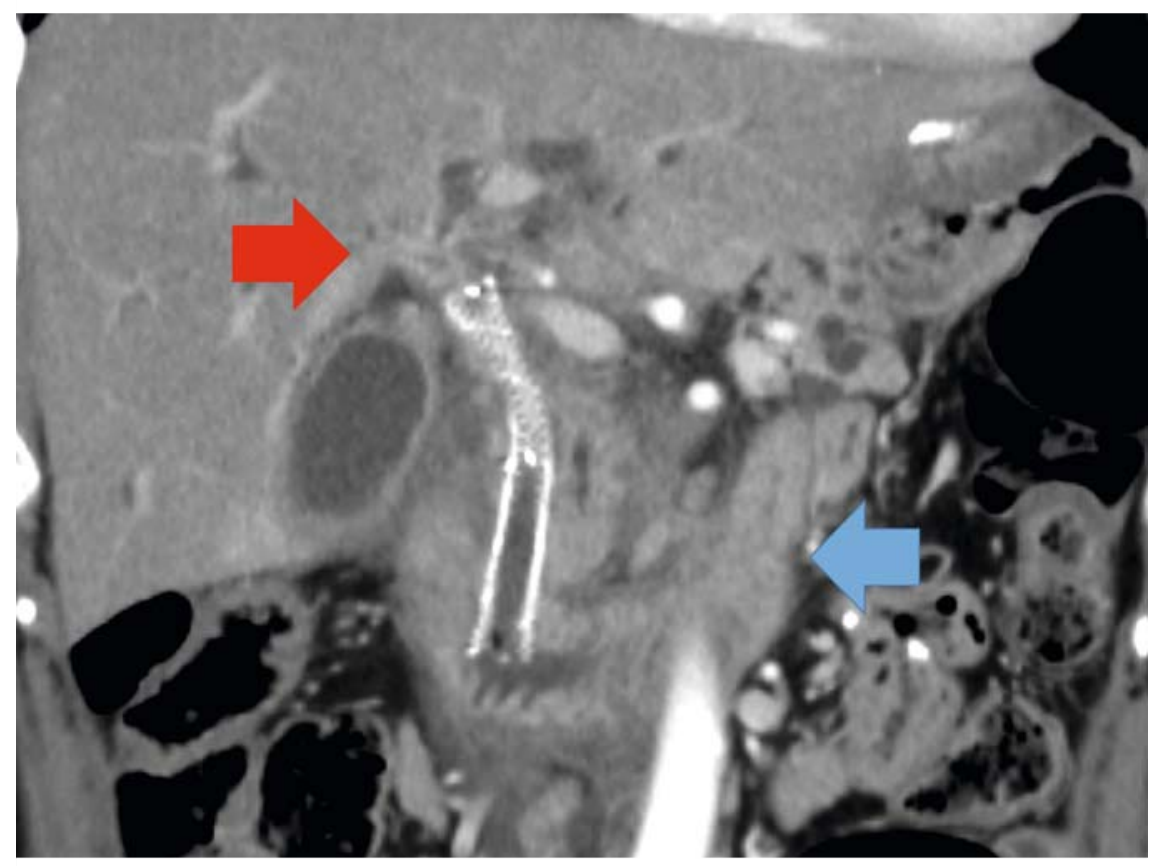

- Fig. 1 Contrast-enhanced computed tomography image showing strictures of the hilar bile duct (red arrow) and duodenum (blue arrow) associated with the dissemination of gastric cancer.

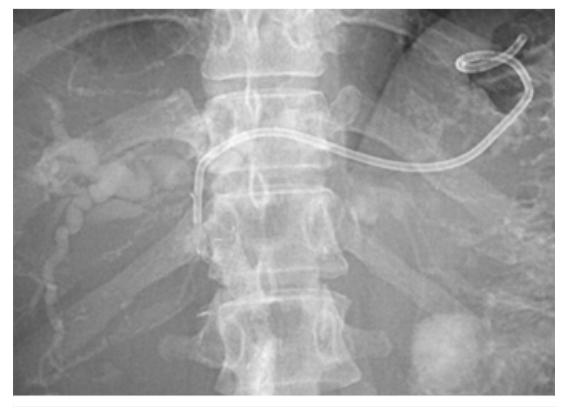

Fig. 2 Endoscopic ultrasound-guided hepaticogastrostomy was performed and a 7-Fr plastic stent was placed into the B3 bile duct.

Endoscopy_UCTN_Code_TTT_1AR_2AZ

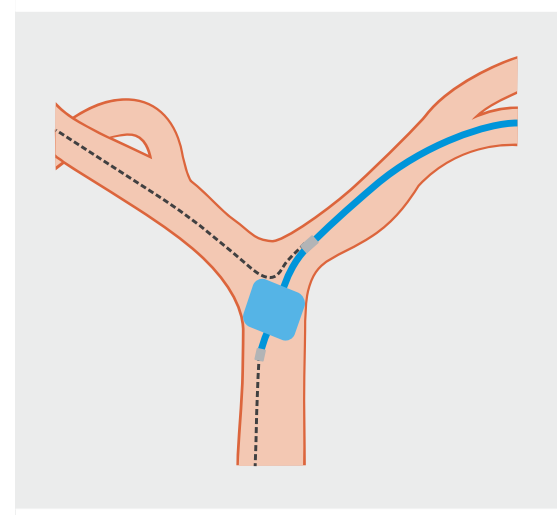

- Fig. 3 The multipath occlusion balloon (Bouncer; Cook Medical, Tokyo, Japan) has a multilumen located at either end of the balloon, which enables guidewires to be passed easily into crooked bile ducts.

\section{Competing interests}



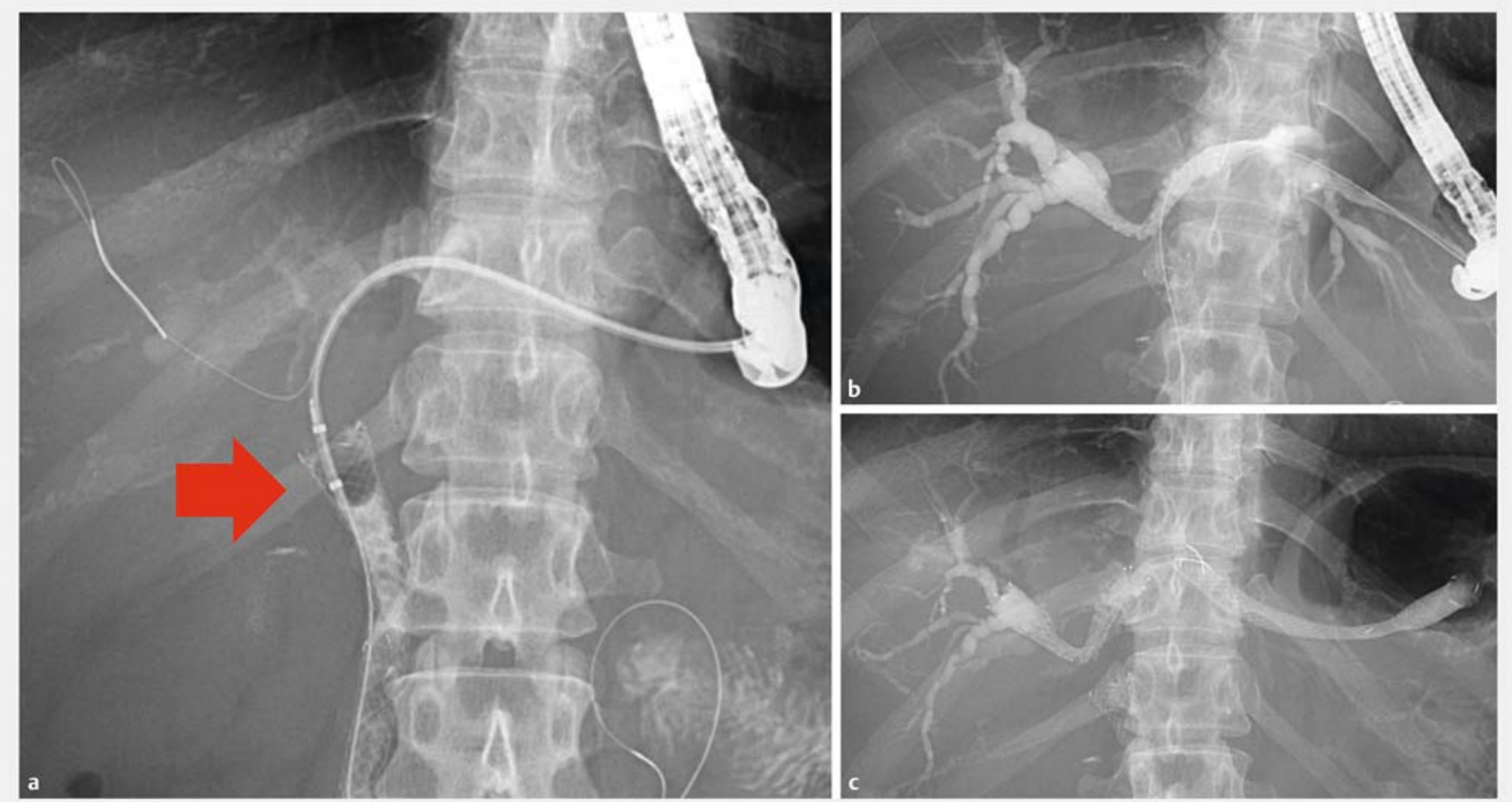

Fig. 4 Radiographic images showing: a a guidewire placed into the B5 bile duct using a multipath occlusion balloon (red arrow); b a self-expandable metal stent (SEMS) introduced over the first guidewire and placed into the B5 bile duct, bridging the right and left hepatic ducts; c a second SEMS placed into the B3 bile duct bridging the hepatogastric stoma.

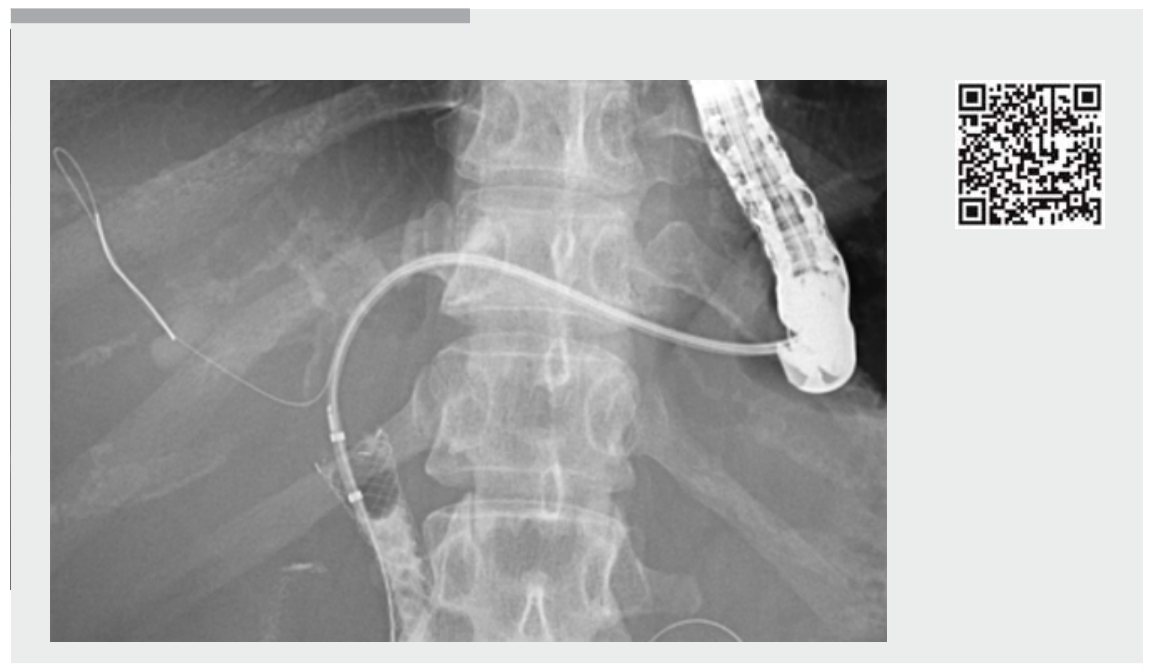

Video 1 Re-intervention with endoscopic ultrasound-guided hepaticogastrostomy (EUS-HGS). Drainage of the right hepatic duct was challenging, but we achieved technical success using a multipath occlusion balloon.
The authors

\section{Daisuke Uchida, Hironari Kato, Hiroyuki \\ Okada}

Department of Gastroenterology, Okayama University Hospital, Okayama, Japan

\section{Corresponding author}

\section{Daisuke Uchida, MD, PhD}

Department of Gastroenterology, Okayama University Hospital, 2-5-1 Shikata-cho,

Okayama 700-8558, Japan

Fax: +81-86-2255991

d.uchida0309@gmail.com 


\section{References}

[1] Paik WH, Lee NK, Nakai Y et al. Conversion of external percutaneous transhepatic biliary drainage to endoscopic ultrasound-guided hepaticogastrostomy after failed standard internal stenting for malignant biliary obstruction. Endoscopy 2017; 49: $544-548$

[2] Ogura T, Kitano M, Takenaka M et al. A multicenter prospective evaluation study of endoscopic ultrasound-guided hepaticogastrostomy combined with antegrade stenting (with video). Dig Endosc. doi:10.1111/ den.12976

[3] Koshitani T, Nakagawa S, Itoh Y. EUS-guided antegrade stent placement for unresectable malignant hilar biliary strictures by use of a stent-in-stent method. Gastrointest Endosc 2018; 87: 309-310

[4] Umeda ], Itoi T, Tsuchiya T et al. A newly designed plastic stent for EUS-guided hepaticogastrostomy: a prospective preliminary feasibility study (with videos).

Gastrointest Endosc 2015; 82: 390 - 396

\section{Bibliography}

DOI https://doi.org/10.1055/s-0044-100719

Published online: 2.2 .2018

Endoscopy 2018; 50: 450-452

(c) Georg Thieme Verlag KC

Stuttgart · New York

ISSN 0013-726X

\section{ENDOSCOPY E-VIDEOS}

https://eref.thieme.de/e-videos

回的 Endoscopy E-Videos is a free access online section, reporting 田: on interesting cases and new techniques in gastroenterological endoscopy. All papers include a high quality video and all contributions are freely accessible online.

This section has its own submission website at

https://mc.manuscriptcentral.com/e-videos 